\title{
The role of relative deprivation in majority-culture support for multiculturalism
}

\author{
Zoe Leviston $^{1}$ (1) | Justine Dandy ${ }^{1}$ | Jolanda Jetten ${ }^{2}$ | lain Walker,4
}

\author{
${ }^{1}$ School of Arts \& Humanities, Edith Cowan \\ University, Joondalup, WA, Australia \\ ${ }^{2}$ School of Psychology, University of \\ Queensland, Brisbane, QLD, Australia \\ ${ }^{3}$ School of Psychology and Counselling, \\ University of Canberra, Canberra, ACT, \\ Australia \\ ${ }^{4}$ Research School of Psychology, Australian \\ National University, Canberra, ACT, \\ Australia
}

\section{Correspondence}

Zoe Leviston, School of Arts \& Humanities, Edith Cowan University, 270 Joondalup

Drive, Joondalup, WA 6027, Australia.

Email: z.leviston@ecu.edu.au

Funding information

Edith Cowan University, Grant/Award Number: 31763

\begin{abstract}
In this paper, we investigate majority-culture attitudes to multicultural policy in Australia. Drawing on relative deprivation (RD) theory, we explore whether resistance to multicultural policies and initiatives is related to individual and/or groupbased grievance claims of discrimination. To assess RD, we asked 517 Australian-born people who identified as White Australians to rate (a) levels of discrimination toward their own group, toward themselves personally as a consequence of their group membership, and toward immigrants to Australia, and (b) feelings of injustice and anger associated with such discrimination. Our findings show that, while perceptions of discrimination toward majority-culture Australians are commonplace, perceptions of discrimination toward immigrants are more so. We also found that higher ratings of group-based RD of Australians relative to immigrants, but not individual deprivation relative to immigrants, predicted opposition to multicultural policies and initiatives. Moreover, perceived group-based RD mediated the link between national identification and opposition to multicultural policies. The findings highlight, for the first time, the importance of group-based grievance claims by majority-culture members in opposing or supporting multicultural policy.
\end{abstract}

\section{1 | INTRODUCTION}

Populist politics have surged in many western democracies, invigorated by renewed debates about the merits of multiculturalism and immigration. This rise has been attributed to a widespread sense of grievance among majority-culture individuals, due to real or perceived deprivation and disenfranchisement. For instance, mainstream media have often cited economic hardship and an increased sense of marginalization among majority-culture members as key reasons for the U.K.'s decision to leave the European Union, and the election of Donald Trump to the U.S. presidency (Jack, 2016; Pettigrew, 2017). Political accounts of the rise of populism have tended to focus on individual-level disadvantage, implicating socio-demographic factors thought to indicate the economic "losers" of globalization, in driving hip-pocket voting responses by a disenfranchised public (Hobolt, 2016). However, the objective evidence linking personal economic deprivation and vulnerability with populism is tenuous at best (Jetten, Mols, \& Postmes, 2015; Pettigrew,
2017). Moreover, a focus on personal and economic disenfranchisement alone risks ignoring the centrality of groups in much of the current political and community discourse: populist political movements are collective social movements at their core. Therefore, a logical approach is to investigate collective perceptions of groupbased disadvantage. This is the focus of the present paper.

We suggest that group identity, group entitlement, and intergroup threat frame national conversations about immigration and cultural diversity, and shape responses to national policy. In this paper, we draw on relative deprivation (RD) theory to examine the following questions. First, we ask whether a sense of RD, as measured by perceived discrimination, among members of a majority-culture group explain responses to policies designed to assist minority groups. Second, we examine whether group-based RD or individual RD is more strongly associated with responses to multicultural policy. Third, we examine whether group-based RD better predicts policy responses than more objective indicators of disadvantage-specifically, social status, educational attainment, and employment status. Fourth, we examine whether 
group-based RD can account for associations between national identity and support for multiculturalism.

\section{1 | Relative deprivation}

Relative deprivation (RD) refers to a sense of grievance stemming from an invidious social comparison. The emotion of RD is conceptualized as a type of anger, emerging from the sense that one has been unjustly deprived of something desired (Crosby, 1976) For RD to be present, an individual must sense they are (a) either individually or collectively worse off on some status dimension relative to a comparison referent, (b) that this difference is unfair, and (c) the individual must feel angry and resentful about the perceived difference (Walker, Leviston, Price, \& Devine-Wright, 2015). The three constituent parts of RD logically lend its application to understanding the experience of traditionally marginalized peoples. Indeed, RD has been applied almost exclusively to minority groups, often "racial" and ethnic minorities and women, to predict outcomes such as mental and physical health, group-based attitudes, and collective action (Smith, Pettigrew, Pippin, \& Bialosiewicz, 2012). There is some evidence to suggest, though, that the construct has utility in understanding the responses of the objectively advantaged (e.g. Leach, lyer, \& Pedersen, 2007). We use this latter application of RD in the current study.

RD can occur via various types of social comparisons between individuals and groups. One may feel deprived relative to another person, relative to a group of people (either one's in-group or outgroup), or one may feel one's group as a whole is deprived relative to another group. These intergroup comparisons are principally pertinent to political and policy responses, particularly when policies are targeted toward societal groups. Applying different types of deprivation to predict support for both populist and African American political candidates, Vanneman and Pettigrew (1972) found that group-based comparisons best predicted responses to social change, while individual-level comparisons were relatively unimportant. They concluded by warning against an individualistic bias in RD research, whereby a tendency to study an individual's situation compared to others comes at the exclusion of perceptions of RD at a group level. More recent studies support the suggestion that group-based perceptions of deprivation are more strongly linked to collective responses (such as social protest) and attempts to improve the group's collective situation (Abrams \& Grant, 2012; Smith \& Ortiz, 2002). The experience and outcomes of RD are generally matched at scale; feelings of personal RD lead to individual-level outcomes, such as stress, and group RD leads to group-level outcomes, such as engaging in social demonstration on behalf of the group (Walker, 1999). As such, we would expect perceptions of group RD to take primacy in predicting policy outcomes aimed at the group level.

The specific social comparison, or status dimension, that forms the basis of the grievance in RD is context-specific. Much of the
RD literature operationalizes grievances in economic terms. For instance, Vanneman and Pettigrew (1972) framed African American/ White American RD perceptions in terms of "economic gains compared to" in-group or out-group workers. However, concentrating solely on perceived economic grievances risks overlooking less material forms of deprivation, such as perceived symbolic or cultural losses (Riek, Mania, \& Gaertner, 2006). Other researchers have operationalized RD as a general sense of "being worse off" (Ellemers \& Bos, 1998), or used perceptions of "discrimination and deprivation" across multiple dimensions, including job opportunities, access to social services, and education (Petta \& Walker, 1992).

Here, we operationalize RD as majority-culture perceptions of discrimination toward two groups, White Australians (in-group), and immigrants to Australia (out-group), and toward themselves (personal) as a consequence of their ethnic membership. We use perceived discrimination, and feelings of unfairness and anger associated with that discrimination, to assess RD, as this reflects the dominant discourse accompanying current narratives of majority-culture "disenfranchisement" in Australia (which we will explain in greater detail below). The outcome variable of interest in the current research is support for/opposition to multicultural policies designed to assist immigrants settle in Australia.

\section{2 | RD among majority groups}

Current theorizing about political populism implicates the role of an increasing sense of disenfranchisement among majority-culture group members for its recent re-emergence; this is not confined to a sense of economic disenfranchisement, but encompasses a sense of "loss" in social and cultural spheres (see Clarke \& Newman, 2017, for a discussion). The extent to which majority-culture members perceive such "loss," and whether they are aggrieved about it, is not clear though.

Why might RD occur among objectively advantaged groups? One potential explanation concerns the concept of zero-sum thinking; the subjective interpretation that out-group gains necessarily come at the expense of in-group losses (Norton \& Sommers, 2011). If minority groups are perceived as having made gains on some important status dimension, then this may be judged as having come at the expense of the majority group, who may then infer that they have (or will) become relatively deprived on that dimension.

Another potential explanation concerns the role of populist leaders and sections of the media commentariat in promoting and perpetuating narratives about the increasing disenfranchisement of the majority group. For instance, in an analysis of populist leader speeches, Mols and Jetten (2016) identified common rhetorical strategies designed to recast the objective relative gratification of the majority group into a sense of RD, in order to foster opposition to minority-targeted government policy. Relatedly, 
LeBlanc, Beaton, and Walker (2015) found that alerting members of an advantaged group to a possible decline in their status, via a manipulation, predicted higher prejudice toward an out-group.

Relatively few studies have directly employed perceptions of RD among an objectively advantaged group. Ellemers and Bos (1998) investigated perceptions of deprivation with native entrepreneurs in Amsterdam compared with their immigrant colleagues. They found that, despite objective indicators to the contrary, native shopkeepers felt deprived as a group (as measured by a sense that their group's "situation" was worse than other entrepreneurs'). Their deprivation levels could not be explained by their own business's success or failure, or by feelings of personal deprivation. Rather, shopkeepers' strength of identification with their own group was associated with feelings their group as a whole was deprived. Further, feelings of group-based deprivation, but not feelings of individual deprivation, were related to feelings of animosity toward immigrant shopkeepers.

Other findings suggest that perceptions of group-based RD by majority-group members influence responses to government initiatives. Investigating support for government redress to aid Australia's Aboriginal population, Leach et al. (2007) found that majority-culture Australians perceived their in-group as relatively deprived compared with Aboriginal Australians (as measured by a sense of general "advantage" or "disadvantage"). This perceived deprivation was associated with group-based feelings of anger, in turn promoting greater engagement in political action against government redress for Aboriginal Australians. More recently, Meuleman, Abts, Schmidt, Pettigrew, and Davidov (2019) found that group RD by Europeans was associated with perceived ethnic threat. In a similar vein, Bagci, Stathi, and Piyale (2019) found that, in a high conflict intergroup context (disadvantaged Kurds and advantaged Turks), imagined contact with the disadvantaged group increased both collective active tendencies and, marginally, perceptions of RD among members of the advantaged group.

\section{3 | Personal versus group deprivation, and deprivation on behalf of others}

Investigations on the role of individual and group-based RD have revealed another robust effect: that people judge more deprivation (usually framed in terms of "discrimination") as occurring to their group than to themselves. This phenomenon, termed the "personal/group discrimination discrepancy effect," may help explain the failure to find clear links between individual-level objective indicators of disadvantage and support for populist policies and politicians. One perspective suggests that the personal/group discrimination discrepancy arises as a result of an ego-protective denial of personal discrimination (Taylor, Wright, Moghaddam, \& Lalonde, 1990). Nagata and Crosby (1991) suggest the effect may be triggered by an exaggeration of group suffering to maintain the group's position, exacerbated by faulty informational cues in one's cultural environment, such as media messaging.
This latter perspective is consistent with a counter-finding; Poore et al. (2002) found the discrepancy effect could not be replicated with members of an Inuit community, which the authors attribute to geographical isolation and lack of exposure to mainstream societal cues. There is some evidence that the discrepancy effect also occurs for members of majority groups (e.g., Kobrynowicz \& Branscombe, 1997; Operario \& Fiske, 2001).

In addition to feelings of in-group and personal deprivation, RD on behalf of disenfranchised others-such as immigrants and ethnic minority groups-may also occur. Tougas and Beaton (2001) note that this form of deprivation, whereby people feel discontent upon perceiving unfair treatment of groups to which they do not belong, has received little empirical attention. The little research that does exist has focused on perceptions of intergroup relations between men and women. This research found men's feelings of group-based RD were negatively related to RD on behalf of others (women), suggesting interdependencies between in-group deprivation and deprivation on behalf of others (LeBlanc et al., 2015; Tougas \& Beaton, 2001; Tougas, Beaton, \& Veilleux, 1991). Further, men who felt RD on behalf of others (women) expressed greater support for affirmative action programs targeted toward women. We would, therefore, expect recognition of the deprivation of another group to translate to stronger support for policies designed to ameliorate the inequities suffered by that group.

\subsection{Antecedents of opposition to immigration and multiculturalism}

In the current research, we are interested in understanding whether feelings of RD by a majority-culture underlie opposition to multicultural policies designed to assist immigrants. Several factors are known to predict the rejection of immigration and multiculturalism in Western nations. First, stronger national identification is associated with preferences for assimilationist policies over multicultural policies, more negative views of immigrants, and greater rejection of multicultural ideology (Bourhis \& Dayan, 2004; Dandy \& Pe-Pua, 2010; Fozdar, Spittles, \& Hartley, 2015; Kunovich, 2009; Louis, Esses, \& Lalonde, 2013; Markus, 2017; McAllister, 2018). For majority-group members, national identity typically coincides with ethnic identity (Verkuyten, 2005). This ethno-centric identity is rooted in past forms of collective identity predominantly based on inherited characteristics (ethnicity, race, language) and expressed as a sense of affective attachment to the nation-state (McAllister, 2018). Anti-immigration and anti-diversity sentiment is typically coupled with these more rigid constructions of national identity, which are, in turn, associated with a discourse of entitlement (Dandy \& Pe-Pua, 2013). Drawing from Social Identity Theory, Verkuyten (2005) has argued these associations emerge because pluralist ideologies like multiculturalism threaten the social, political, and economic power of the majority, who feel they must make room for minorities. Recent research demonstrates that those higher in national identification 
are more responsive to out-group threat messages, which in turn heighten opposition to multiculturalism and immigration (Major, Blodorn, \& Major Blascovich, 2018; Spry \& Hornsey, 2007). ${ }^{1}$

From the perspective of RD theory, group identification is usually conceptualized as causally preceding RD, as strong in-group identification is thought to be a necessary precursor to recognizing group disparities (Abrams, 1990; Tajfel, 1978; Tropp \& Wright, 1999). There is some empirical evidence to support this directionality (de la Sablonniere \& Tougas, 2008). From this perspective, RD is more likely to emerge as identification with one's group becomes stronger; people who strongly identify with one's group want more for that group, and by extension, are more sensitive to invidious social comparisons (Tougas \& Beaton, 2001; but see Kessler \& Hollbach, 2005 who show a bi-directional relationship).

With regard to multiculturalism, acceptance of government policy designed to assist minority-groups settle in a new country rests upon the recognition of systemic group-based inequality (and hence the fairness and legitimacy of systemic redress). For those who highly identify with the in-group, opposition to government redress might be amplified through a social comparison process that positions the in-group as relatively deprived with reference to the minority group, hence leading in-group members to challenge the entitlement of the recipients of government policy.

\section{5 | Immigration and multiculturalism in an Australia context}

We test our research questions in an Australian context. As elsewhere, Australia is experiencing a resurgence of populism, typified by divisive debate about immigrants. This narrative is spearheaded by the re-emergence of a populist party notable for its hard-line stance against multiculturalism and immigration (Pauline Hanson's One Nation party). Concurrently, the mobilization of anti-Islamic protest groups and an increasingly volatile debate in mainstream media about "reverse discrimination" toward majority groups has arisen (SBS News, 2016, November 24). These phenomena share an important characteristic-each rests on a grievance claim that repositions majority-culture Australians, as a group, as the new victims of discrimination based on their cultural membership. Within this national context, we argue that perceived discrimination becomes a highly salient and important status dimension upon which groupbased grievance claims rest.

To more fully understand the context in which hypotheses are tested, it is important to describe the historical context in which present-day narratives of immigration and multiculturalism are situated. Since Federation in 1901, Australia has had an uneasy history with multiculturalism and multicultural policy. One of the first Acts of the new federal Parliament limited immigration to those from Europe who were fluent in English, forming the basis of the longstanding "White Australia policy." This policy, ostensibly enacted to

${ }^{1}$ It should be noted that the content of national identity is also critical to attitudes to out-groups (Pehrson, Brown, \& Zagefka, 2009; Spry \& Hornsey, 2007). protect the jobs and welfare of the existing citizenry, gave way in the 1970 s to bipartisan support for multicultural policies and practices, and a nondiscriminatory immigration program. The transition from cultural assimilation to encouraging the retention of cultural customs and traditions has not been smooth (Jupp, 2002); it is continually contested, punctuated by moments of rancorous debate. One such punctuation was the brief but dramatic rise in the 1990s of rightwing populist politician Pauline Hanson who went on to form the One Nation party. This party's commentary on immigration, multiculturalism, and cultural minorities appeared tailored to appeal to economically disadvantaged "White Australians." Arguably, the populist platform of Pauline Hanson and One Nation was simply a more overt expression of continuing antagonism toward immigrants and multiculturalism harbored by mainstream political parties, particularly those of the center-right. Despite periods of contestation about the merits of multiculturalism, including among mainstream parties, bipartisan political support endures for policies and initiatives designed to help new immigrants to Australia establish themselves socially and economically.

Public attitudes toward multiculturalism, cultural diversity, and immigration have remained, at best, ambivalent (Dandy \& PePua, 2010), and debates about the merits and perils of multiculturalism have recently reignited. The current conservative federal government has once more proposed changes to citizenship requirements, with increased English language literacy requirements and an emphasis on adherence to "Australian values." Pauline Hanson's One Nation party currently enjoys a resurgent media profile as well as support from a significant minority of the electorate (gaining the fourth highest vote in the Senate in the 2016 federal election). New nationalist protest groups have organized rallies-attended by some mainstream political conservatives-to denounce immigration and multiculturalism. And various outspoken media commentators have employed increasingly populist rhetoric to warn "mainstream Australia" (often used interchangeably with the terms "White Australia" and "ordinary Australia") that they are now targets of so-called reverse racism and discrimination (McCauley, 2016). These commentators have questioned the legitimacy of sections of Australia's Racial Discrimination Act, and the Human Rights Commission itself, and have attempted to position mainstream White Australia as victim to an increasingly powerful alliance between minority groups (including migrant groups), left-wing inner-city dwellers, and institutional elites (e.g., Clarke \& Newman, 2017; Donnelly, 2017; Mols \& Jetten, 2016).

\subsection{The current research}

In the present study, we test whether RD-specifically, feeling that one's cultural group is discriminated against relative to others, and that this discrimination is unfair and one feels angry about it-is prevalent among majority-culture members, and how these perceptions relate to support for multicultural policy. Further, we investigate how RD relates to more objective indicators of disadvantage 
(social status, educational attainment, and employment status), socio-demographic variables, and national identity. We test the following hypotheses:

Hypothesis 1 Majority-group members' perceptions of group RD and personal RD will be associated with opposition to multicultural policies, while RD on behalf of a minority group will be associated with support for multicultural policies.

Hypothesis 2 Group RD, and RD on behalf of a minority group, will be a stronger predictor of multicultural policy responses than personal $R D$.

Hypothesis $3 R D$ (a calculation of group $R D$, minus $R D$ on behalf of a minority group, such that higher scores represent greater perceptions of majority-group RD) will be a stronger predictor of opposition to multicultural policy than objective indicators of disadvantage.

Hypothesis 4 RD will mediate the relationship between national identity and opposition to multicultural policy.

\section{2 | METHOD}

\section{1 | Participants and procedure}

An online survey was administered in July 2017 to 517 people who indicated they (a) were born in Australia, and (b) identified as "White Australian." Respondents were recruited through an online survey recruiting and analysis company (Qualtrics panels). Comparable levels of men (47.8\%) and women (51.6\%) completed the survey (with $0.6 \%$ not otherwise stated). Participants ranged in age from 18 to 85 (with a mean date of birth of $1969, S D=17.6$ ). Statistical significance was set at $p<.01$.

\subsection{Measures}

\subsection{1 | Deprivation measures}

Three measures of deprivation based on majority-culture membership were constructed to test the relative influence of group-level deprivation, individual-level deprivation, and deprivation on behalf of others. To reflect the national context (see preceding section), "discrimination" was used as the status dimension. Each measure was comprised of three items, following Walker et al. (2015). The order in which group deprivation and deprivation on behalf of others were presented to participants was randomized to control for order effects attributable to the referent group.

\section{Group relative deprivation (GRD)}

A sense of GRD was assessed by first asking participants "To what extent are White Australians, as a group, a target of discrimination?". Responses were recorded on a 5-point scale, ranging from "1-Not at all" to "5-A great deal," with "3-Somewhat" at the midpoint. Those who provided a response of " 2 " or greater were asked two follow up questions: "How fair do you think this discrimination is?" recorded on a scale of "1-not at all unfair" to "5-extremely unfair," and "How angry and resentful does this discrimination make you feel?" recorded on a scale of "1-not at all angry" to "5-extremely angry." Those who provided a response of "1" to the first question were allocated responses of "1" to the follow up questions. Two measures of GRD were constructed: a binary measure, where the presence of GRD was indicated by scores of 2 or more to each of the three questions; and a continuous measure of GRD, where responses to all three questions were summed (with the resultant score ranging from a minimum of 3 to a maximum of 15).

\section{Personal relative deprivation (PRD)}

A sense of PRD, based on cultural group membership, was assessed using the same method as for GRD, with the wording of the first question amended to read "To what extent are you personally a target of discrimination because of being a White Australian?" Two measures of PRD were constructed-a binary measure and a continuous measure-following the same procedure as for GRD.

Relative deprivation on behalf of the minority-group (RDBM)

A sense of RDBM was assessed using the same method as for GRD, with the wording of the first question amended to read "To what extent are immigrants to Australia, as a group, a target of discrimination?" Two measures of RDBM were constructed-a binary measure and a continuous measure-following the same procedure as for GRD.

\subsection{2 | Support for multicultural policy}

A Multicultural Policy scale consisting of seven items assessed participants' support for policies and initiatives designed to assist new immigrants settle in Australia. These items were derived from the Australian Federal Government's Multicultural Statement (Australian Government, 2017), which details current policies and initiatives. Participants were asked the degree to which they agreed with government investing in a series of initiatives, including access schemes for additional social services for people from different cultural backgrounds, and resettlement services to help improve employment outcomes for immigrants. Responses were provided on a 5-point scale, from "1-Strongly disagree" to "5-Strongly agree" (Cronbach's alpha $=.88$ ). Standard deviations and means for each item in the scale are included in Table S1. The Cronbach's alpha of the scale was not improved by the removal of any items. As the Multicultural Policy scale was a newly constructed measure, Berry's (2006) 10-item measure of Multicultural Ideology was included to assess the validity of the Multicultural Policy scale, as Berry's measure is an established measure used to assess the extent to which participants view cultural diversity as good for a society and its members (Cronbach's alpha = .88). 


\subsection{3 | Social status}

Cantril's (1965) self-anchoring scale, in the form of a 10-rung ladder, was used to measure participants' social status. Participants were shown an image of this ladder with the following instructions: "Think of this ladder as representing where people stand in society. At the top of the ladder are the people who are best off-those who have the most money, most education and the best jobs. At the bottom are the people who are worst off-who have the least money, least education and the worst jobs or no job. The higher up you are on this ladder, the closer you are to people at the very top and the lower you are, the closer you are to the bottom. Where would you put yourself on the ladder?" Responses were recorded on a 10-point scale from "1-Worst off" to "10-Best off."

\subsection{4 | Other demographic variables}

Education was measured by asking participants to select their highest level of educational attainment, ranging from "1-some or all of primary school" to "10-completed postgraduate qualification." Employment status was measured by asking participants to select which of the following best reflected their current status: employed full-time, employed part-time, unemployed but seeking employment, or other. Political orientation was measured by asking participants to move a slider to the place on the scale, marked from "0-more left wing" to "100-more right wing," that best represented their political orientation. Participants' age was measured by asking them to indicate their year of birth.

\subsection{5 | National identity}

National identity was measured by five items adapted from the Turken and Rudmin (2013) Scale of Global Identity. Example items are "I feel most connected to members of my own country" and "I feel intense pride when I think about my country." Responses were provided on a 5-point scale, from "1-Strongly disagree" to "5Strongly agree" (Cronbach's alpha = .83).

\section{3 | RESULTS}

\section{1 | Preliminary analyses}

\subsection{1 | Binary measures of group relative deprivation, personal relative deprivation, and relative deprivation on behalf of minority group}

In total, $65.4 \%$ of participants reported at least some level of group deprivation, $56.7 \%$ reported some level of individual deprivation, and $81.4 \%$ reported some level of deprivation on behalf of immigrants to Australia.

\subsection{2 | Continuous measures of group relative deprivation (GRD), personal relative deprivation (PRD), and relative deprivation on behalf of minority group (RDBM)}

As expected, significantly higher levels of GRD were reported than PRD, $t(516)=11.64, p<.001$ (Table 1). Reported levels of RDBM were significantly higher than both GRD, $t(516)=-9.51, p<.001$, and PRD, $t(516)=-16.72, p=<.001$. Men reported greater levels of GRD and PRD (GRD: $M=8.49, S D=3.70 ; P R D: M=6.94 ; S D=4.06$ ) than women, GRD: $M=7.57, S D=3.70, t(512)=-2.85, p=.005$; PRD: $M=5.84 ; S D=3.82, t(512)=-3.17, p=.002$, although in both cases the effect was small $\left(\eta^{2}=.02\right)$. Women reported greater levels of $\operatorname{RDBM}(M=10.25 ; S D=2.95)$ than men, $M=9.59 ; S D=2.78, t(512)=$ $2.59, p=.01$, although again the effect was small $\left(\eta^{2}=.01\right)$.

There was a strong positive relationship between reported levels of GRD and PRD (.65, $p$.001) (Table 1). There was no significant relationship between GRD and RDBM (-.02, $p=.69)$, or between PRD and RDBM (.003, $p=.95)$.

The multicultural policy support scale was highly correlated with Berry's (2006) multicultural ideology scale $(r=.71, p<.001)$, indicating good construct validity of the new policy support scale. As hypothesized (hypothesis 1), GRD and PRD were moderately and negatively related to multicultural policy support, and RDBM was moderately and positively related to policy support.

TAB LE 1 Correlation matrix for perceived deprivation levels, socio-demographic variables, and policy support

\begin{tabular}{|c|c|c|c|c|c|c|c|c|c|}
\hline & Mean & $S D$ & 1 & 2 & 3 & 4 & 5 & 6 & 7 \\
\hline 2. Individual deprivation (PRD) & 6.35 & 3.97 & $.65^{* *}$ & & & & & & \\
\hline $\begin{array}{l}\text { 3. Deprivation on behalf of } \\
\text { minority-group (RDBM) }\end{array}$ & 9.96 & 2.90 & -.02 & .00 & & & & & \\
\hline 4. Age & 47.5 & 17.60 & $.10^{*}$ & $-.10^{*}$ & $-.26^{* *}$ & & & & \\
\hline 6. Social status & 5.34 & 1.93 & .00 & .02 & .05 & $-.18^{* *}$ & $.34^{* *}$ & & \\
\hline 7. Political orientation & 48.11 & 22.24 & $.31^{* *}$ & $.18^{* *}$ & $-.21^{* *}$ & $.16^{* *}$ & -.00 & $.23^{* *}$ & \\
\hline 8. Policy support & 3.52 & .89 & $-.33^{* *}$ & $-.27^{* *}$ & $.46^{* *}$ & $-.10^{*}$ & $.13^{* *}$ & $.14^{* *}$ & $-.26^{* *}$ \\
\hline
\end{tabular}

${ }^{*} p<.01 ;{ }^{* *} p<.001$. 
GRD was weakly and positively associated with age, and moderately related to right-wing political orientation. PRD was weakly and negatively associated with age, and weakly related to right-wing political orientation. RDBM was moderately and negatively associated with age, and moderately associated with left-wing political orientation. Policy support was only weakly associated with age, educational attainment, and social status, and unrelated to employment status, $F(3,513)=1.05, p=.37$. Deprivation scores were unrelated to social status. A series of one-way analyses of variance revealed no significant differences in deprivation scores based on participant employment status, GRD: $F(3,513)=1.10, p=.35$; PRD: $F(3,513)=$ $1.34, p=.26 ; \operatorname{RDBM}(3,513)=1.12, p=.31$.

To test hypothesis 2 , a regression analysis was performed to examine the unique contribution of the different types of deprivation on support for multicultural policy (Table 2). Together, perceptions of deprivation accounted for $32 \%$ of the variance in levels of policy support. As hypothesized, only GRD and RDBM uniquely predicted support; PRD failed to reach significance ( $p=.03$ ). As GRD and PRD were highly correlated, a second regression was performed to test whether PRD became significant with the removal of RDBM. Together, GRD and PRD explained $11 \%$ of the variance in policy support, however, PRD again failed to reach significance $(\beta=-.09, p=$ .10). A third regression was performed with GRD and RDBM and an interaction term between the two independent variables. Together, the model accounted for $33 \%$ of the variance in policy support. GRD ( $\beta=-.61, p<.001)$ and $\operatorname{RDBM}(\beta=.29, p<.001)$ were both significant. The interaction term approached statistical significance at the
.01 level ( $\beta=.37, p=.011$ ), providing tentative evidence that policy opposition is highest when in-group deprivation is high and deprivation on behalf of the minority group is low.

\section{2 | Constructing a measure of RD}

As individual deprivation did not uniquely predict variance in policy support, it was discarded from further analysis. To assess the ability of relative group-based deprivation assessments to explain multicultural support relative to objective indicators of disadvantage (hypothesis 3), and to test the mediating role of group-based RD (hypothesis 4), a difference score to denote group-based RD was computed by subtracting levels of RDBM (deprivation on behalf of the minority group) from GRD (group deprivation). Higher scores indicated greater levels of perceived in-group deprivation (White Australians) relative to an out-group (immigrants to Australia).

A majority of participants (57.1\%) had negative RD scores, indicating greater levels of perceived out-group discrimination relative to their in-group. Roughly one-quarter of participants (25.7\%) had positive RD scores, indicating greater levels of perceived in-group discrimination relative to the out-group. The remaining $17.2 \%$ of participants had an RD score of 0 , indicating perceptions of equivalent in-group and out-group discrimination.

The resulting measure's correlation with key variables is shown in Table 3. RD was negatively and weakly related to educational attainment, and moderately and positively related to age, right-wing
TABLE 2 Simultaneous regressions of the influence of deprivation measures on multicultural policy support

\begin{tabular}{lllll} 
& \multicolumn{4}{l}{ Multicultural policy support } \\
\cline { 2 - 5 } & $\boldsymbol{b}$ & SE $\boldsymbol{b}$ & $\boldsymbol{\beta}$ & \multicolumn{1}{c}{} \\
\hline Constant & 2.76 & .14 & $20.20^{* *}$ & $44.25^{* *}$ \\
\hline Group deprivation (GRD) & -.06 & .01 & -.26 & $-5.32^{* *}$ \\
\hline Individual deprivation (PRD) & -.02 & .01 & -.10 & -2.14 \\
\hline $\begin{array}{l}\text { Deprivation on behalf of } \\
\text { minority group (RDBM) }\end{array}$ & .14 & .01 & .46 & $12.56^{* *}$ \\
& $R^{2}=.32$ & & & \\
\hline
\end{tabular}

${ }^{*} p<.01 ;{ }^{* *} p<.001$

TAB LE 3 Correlation matrix for relative deprivation and key variables

\begin{tabular}{|c|c|c|c|c|c|c|c|c|}
\hline & Mean & $S D$ & 1 & 2 & 3 & 4 & 5 & 6 \\
\hline 2. Age & 47.5 & 17.60 & $.23^{* *}$ & & & & & \\
\hline 3. Education & 5.80 & 2.24 & $-.13^{* *}$ & $-.22^{* *}$ & & & & \\
\hline 4. Social status & 5.34 & 1.93 & -.03 & $-.18^{* *}$ & $.34^{* *}$ & & & \\
\hline 5. Political orientation & 48.11 & 22.24 & $.37^{* *}$ & $.16^{* *}$ & -.00 & $.23^{* *}$ & & \\
\hline 7. Policy support & 3.52 & .89 & $-.54^{* *}$ & $-.10^{*}$ & $.13^{* *}$ & $.14^{* *}$ & $-.26^{* *}$ & -.28 \\
\hline
\end{tabular}

${ }^{a}$ Relative deprivation score calculated by subtracting deprivation of behalf of the minority group scores from perceived in-group deprivation scores (Range: Min $=-12, \operatorname{Max}=12$ )

${ }^{*} p<.01 ;{ }^{* *} p<.001$. 
political orientation, and national identity. RD had the strongest association (negatively) with multicultural policy support.

A simultaneous multiple regression was performed to test the predictive power of RD on policy support in relation to objective indicators of disadvantage (hypothesis 3). RD, social status, educational attainment, and employment status [dummy coded] predicted $32 \%$ of the variance in policy support. As hypothesized, RD was a stronger predictor of policy responses $(\beta=-.54, p<.001)$ than social status ( $\beta=.13, p=.002)$, educational attainment $(\beta=$ $.04, p=.35$ ), and employment status (employed: $\beta=-.09, p=.04$; part-time employed: $\beta=-.05, p=.19$; unemployed seeking work: $\beta=-.07, p=.09$ ).

\section{3 | The mediating role of RD}

To test whether RD helps explain the link between national identity and opposition to multicultural policy (hypothesis 4), multiple regression analyses were conducted to assess each component of a proposed mediation model (Figure 1). First, national identity was negatively associated with policy support, $F(1,515)=45.16$, $p<.001, R^{2}=.08, b=-.29, t(514)=-6.72, p<.001$, and with RD, $F(1,515)=114, p<.001, R^{2}=.18, t(514)=-12.78, p<.001$. The mediator, RD, was negatively associated with policy support, $b=$ $-.10, t(513)=-12.52, p<.001$. Mediation analysis was conducted using the bootstrapping method with bias-corrected confidence intervals (Mackinnon, Lockwood, \& Williams, 2004; Preacher \& Hayes, 2008). The $95 \%$ confidence intervals of the indirect effects were obtained with 5,000 bootstrap samples (Preacher \& Hayes, 2008). The mediation analysis confirmed the hypothesized mediating role of $\mathrm{RD}$ in the relationship between national identity and policy support ( $b=-.22 ; \mathrm{Cl}=-.28$ to -.17 ). Further, the direct effect of national identity on policy support became small and nonsignificant, $b=-.07, t(513)=-1.61, p=.11, Z=-8.11, p<.001$, as shown in Figure 1. This supports the proposition that the majority of the relationship between national identity and policy support is explained by RD.

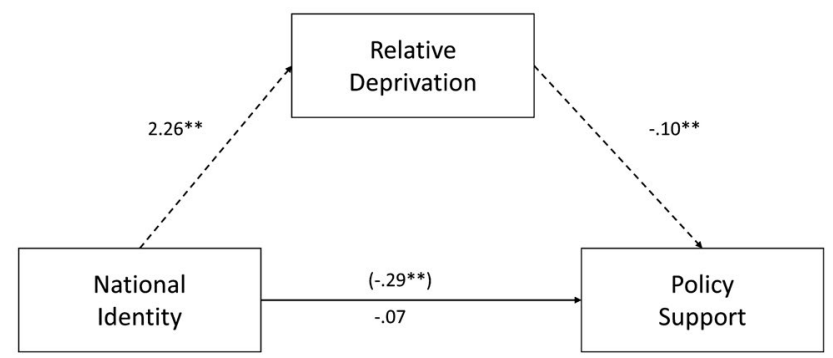

FIGURE 1 Indirect effect of national identity on multicultural policy support through relative deprivation. Figure in parentheses indicates the direct effect. Coefficients are unstandardized. ${ }^{*} p<.01 ;{ }^{* *} p<.001$

\section{4 | DISCUSSION}

We sought to test whether RD is a useful construct to understand majority-culture Australians' grievance claims in the context of immigration and multiculturalism, using perceived discrimination as a status dimension. We found that perceptions of discrimination toward majority-culture Australians on the basis of their cultural group are commonplace, with two-thirds of our sample reporting at least some in-group deprivation and just over half reporting at least some individual deprivation. Deprivation on behalf of the minority group was more widely reported however, with four-fifths reporting at least some deprivation on behalf of immigrants. As indicated by the continuous measure of RD, deprivation on behalf of others was more strongly felt than in-group deprivation, as well as being more commonly reported.

Levels of group-based deprivation predicted support for multicultural policy in the expected way: those who reported higher in-group and personal deprivation were more likely to oppose policy, while those who reported higher deprivation on behalf of immigrants were more likely to support policy. This indicates that social comparison processes and attendant grievance claims are important phenomena to consider when seeking to account for collective challenges to policies designed to assist disadvantaged groups.

Consistent with previous research (Smith \& Ortiz, 2002; Tougas \& Beaton, 1992; Vanneman \& Pettigrew, 1972), group-based perceptions of deprivation were primary predictors of support for multicultural policy; perceptions of personal deprivation were irrelevant. Our results also suggested these group-based grievance claims better predicted policy response than more objective indicators of personal disadvantage, such as social status, educational attainment, and employment status. This finding is also consistent with recent work on collective discontent (van der Bles, Postmes, LeKander-Kanis, \& Otjes, 2018; van der Bles, Postmes, \& Meijer, 2015). These authors found that collective pessimism about society in general is largely decoupled from personal wellbeing. Further, they found that while collective societal discontent predicted voting for extreme parties, including those with anti-immigration and anti-multiculturalism platforms, personal discontent did not (van der Bles et al., 2018). The authors conclude that, even without direct personal experience of societal problems, people may still perceive society as problem-ridden. This conclusion resonates with the current finding that, on aggregate, people thought they were less a victim of personal discrimination than was their group as a whole.

Recognition of discrimination against the minority-group, a sense that this discrimination was unfair, and attendant anger about this discrimination, better predicted support for multiculturalism than did a sense of in-group deprivation. This sits well with previous findings that majority-group members who feel deprived on behalf of others are more likely to support ameliorative policies designed to address group-based inequities (Tougas et al., 1991). It also reflects the prevalence of majority-group "allies" in driving social change on behalf of disadvantaged groups (although this is not without its problems, see Droogendyk, Wright, Lubensky, \& Louis, 2016). More surprising though, and contrasting with previous research (Tougas \& Beaton, 
2001), deprivation on behalf of others was not negatively related to perceived in-group deprivation; rather, the two ratings were unrelated. This suggests that, in the current context, these forms of deprivation may be distinct, and perceptions about group-based deprivation are not necessarily the entrenched, polarized social positions often portrayed in the media, but intra-psychically contested as well. It is also counter to an egoistic or "zero-sum" view of discrimination; that the gains of one group come at the expense of another (Norton \& Sommers, 2011).

As with previous research, the current findings showed those higher in national identity were more opposed to multicultural policies and practices (Louis et al., 2013; McAllister, 2018). Importantly, perceptions of group-based RD played an important explanatory role in these associations, significantly mediating the link between high national identity and policy opposition. This is tentative evidence that strong in-group identification may influence group-based social comparison processes, which in turn shape responses to groupbased policy. It is consistent with theorizing in the RD literature that sensitivity to invidious social comparisons increases as a function of in-group identity (de la Sablonniere \& Tougas, 2008; Tougas \& Beaton, 2001). From this perspective, such sensitivity arguably affords populist politicians and commentators increased purchase in delivering a message of majority-culture discrimination. Another plausible interpretation of this finding is that stronger identification with the out-group, immigrants (perhaps cultivated through social networks or family history), increases sensitivity to an invidious social comparison on behalf of others. Such an interpretation remains to be tested, however.

\section{1 | Implications, limitations, and future directions}

Taken together, our results suggest that perceptions of group-based $\mathrm{RD}$ are important for understanding some of the individual variance in responses to group-based policy responses. That people judged more discrimination as occurring to their group than to themselves reflects a phenomenon termed the "personal/group discrimination discrepancy effect" (Taylor et al., 1990). This phenomenon may help explain the failure here and elsewhere to find strong links between more objective indicators of deprivation-such as education, social status, and employment-and support for populist policies and politicians. The prevalence of "reverse discrimination" arguments in the media and on the political fringes arguably heightens the salience of social comparisons, particularly for people who regularly access media outlets, where such arguments are more commonplace. Coupled with particular ideological and identity characteristics, these processes may cascade to the point where a significant proportion of the majority-culture believes that they are more discriminated against than the minority-culture, as indeed we found was the case with one-quarter of our sample. Further research might explore the influence of different media consumption patterns on personal/group discrepancy effects for majority-group members, and their interrelation with different political ideologies and national identities.
Given the importance of the content of national identity in predicting attitudes toward out-groups (Pehrson et al., 2009), our results suggest that for majority Australians, social representations of national identity still have a strong ethnic element, possibly reinforced by past and present political (and politicized) constructions of national identity. This conflicts with a strong cultural narrative that multiculturalism is a fundamental component of an Australian identity (Australian Human Rights Commission, 2014). Further research might investigate more nuanced forms of identity such as those addressed by Sumino (2017) and others (e.g., Reijerse, Van Acker, Vanbeselaere, Phalet, \& Duriez, 2013; Verkuyten \& Martinovic, 2015). Exploring competing representations of national identity (such as the civic, national, and cultural representations studied by Reijerse et al. (2013) and others), their relationships with RD, and attitudes toward immigration and multicultural policy might further illuminate the relationships found here.

Several limitations of the current study should be acknowledged and addressed in future research. First, our data are cross-sectional, so the directionality implied in our analyses is assumed. For instance, although group identification is often thought to precede RD, experimental testing of this relationship is rare (see de la Sablonniere \& Tougas, 2008; Walker, 1999, for exceptions). Other theoretical explanations of the link between identity and RD posit that ingroup identification is strengthened as a result of perceived group disparities (Branscombe, Schmitt, \& Harvey, 1999), and even RD theorists acknowledge that invidious social comparisons have ramifications for aspects of social identity, such as self-esteem, or even devaluation of the group (Tougas \& Beaton, 2001; Walker, 1999). Further, the perceived status of the group, and whether that status is seen as changing, has been found to modulate reactions to invidious comparisons (de la Sablonniere, Tougas, \& Lortie-Lussier, 2009). For naturally occurring groups, longitudinal designs would better capture the feedback loops among identity processes, social comparisons, perceived group status, and outcome variables such as policy support. Further, identification with groups at higher levels of abstraction, such as Identification With All Humanity (Reese, Proch, \& Finn, 2015), might help further unpack the drivers of RD on behalf of minority groups.

Second, we employed a very broad out-group in the current studyimmigrants to Australia. This comparison group encompasses a range of potential sub-groups, from refugees fleeing war-ravaged countries to financially advantaged people from Western countries seeking a better lifestyle. A loose specification of the out-group allows for myriad social comparisons (including upward or downward comparisons). An upward social comparison may be made in a situation, where the individual wants to downplay the structural advantage of their group, and vice-versa. ${ }^{2}$ As the authors of a meta-analysis on 65 RD studies

\footnotetext{
${ }^{2}$ In the current research, the following short open-ended question was included: When you were answering questions about immigrants to Australia, did you have any particular groups of people in mind? Thematic coding revealed four groups: "non-white, various backgrounds"; "immigrants generally"; "Muslims"; "miscellaneous". No statistically significant differences in relative deprivation scores based on these categories were found. However, we suggest that predefining these subgroups may yield significant differences in future research.
} 
point out, we should be wary of mistakenly assuming that two people in a similar social context will use the same comparison standard (Smith et al., 2012). Future experimental research might test the variability of social comparisons when different subgroups are clearly defined and presented to majority-culture members.

Third, it is not clear whether the current findings would replicate outside of Australia. For instance, Smith et al. (2018) have recently demonstrated the important role national and cultural differences play in moderating the relationship between RD and outcomes. The selection of discrimination as a status dimension might be less suitable in other cultural and historical contexts for instance. Moreover, the construction of a policy support outcome measure would necessarily differ from country to country. Future studies might include a broader range of outcome variables, especially those relevant to more extreme collective action than policy support or rejection. Responses such as protesting, voting for extreme parties, and advocating (and participating in) violent action are regrettably prominent features of current debates about immigration and multiculturalism. Although the predictors of collective action and social change among majority members-who are (objectively) advantaged-are less well studied, we would expect RD, as a form of perceived injustice, to motivate collective action on behalf of the majority in-group (van Zomeren, Postmes, \& Spears, 2008) and discourage support for collective action on behalf of minorities, including immigrants (Brylka, Mähönen, Schellhaas, \& Jasinskaja-Lahti, 2015). Understanding the psychological mechanisms, including RD that trigger more extreme responses will continue to be important.

Fourth, while RD successfully predicted responses to multicultural policy, together RD assessments accounted for only $32 \%$ of the variance, leaving the majority of variance in policy responses unaccounted for. Further, the majority of that predictive power was attributable to $\mathrm{RD}$ on behalf of others, suggesting that a sense of in-group grievance is one part of a much larger picture in understanding the motivators of collective action and support for social change. With this in mind, competing explanations for our results should not be discounted. For instance, Noor, Shnabel, Halabi, and Nadler (2012) suggest that majority-group grievance claims about discrimination may arise from a desire to restore a group's moral identity, particularly where one recognizes one's own group is responsible for illegitimate discrimination toward another group (Sullivan, Landau, Branscombe, \& Rothschild, 2012).

Finally, how different types of perceived deprivation-toward one's own group and on behalf of other groups-coexist and compete within individuals, and how this might manifest as ambivalent attitudinal responses to multiculturalism, is worth unpacking in future research.

\section{5 | CONCLUSION}

In the wake of Brexit, the election of Trump, and the general rise of anti-immigration and anti-multicultural groups in many parts of the Western world, our results support the importance of looking beyond individual-level feelings of disenfranchisement. One does not have to feel personally aggrieved, or experience personal hardship, to feel relatively deprived. Rather, it is individuals' group-based memberships, alliances, and affinities that energize people's responses. Unpacking the bases of these group-based grievances, and how they are exploited by media commentators, interest groups, and politicians, is critical to the development of strategies to promote intergroup harmony in our current climate.

\section{ACKNOWLEDGMENTS}

This research was supported by Edith Cowan University.

\section{CONFLICT OF INTEREST}

The authors have no conflicts of interest to declare.

\section{DATA ARCHIVING AND SHARING}

Participant informed consent statements did not seek consent for data to be made publicly available, however, data will be made available to individual researchers upon request.

\section{ETHICS STATEMENT}

The research was undertaken in accordance with Australian national Ethical Human Research Policies and with the APA's Code of Conduct. All participants provided informed consent prior to participating, and were free to withdraw at any time without penalty. The study received ethical approval from Edith Cowan University's Human Research Ethics Committee (project number: 18054).

\section{ORCID}

Zoe Leviston (iD https://orcid.org/0000-0002-4969-7916

\section{REFERENCES}

Abrams, D. (1990). Political identity: Relative deprivation, social identity, and the case of Scottish nationalism. London, UK: City University, Economic and Social Research Council.

Abrams, D., \& Grant, P. R. (2012). Testing the social identity relative deprivation (SIRD) model of social change: The political rise of Scottish nationalism. British Journal of Social Psychology, 51(4), 674-689. https://doi.org/10.1111/j.2044-8309.2011.02032.x

Australian Government. (2017). Multicultural Australia: United, strong, successful. Canberra: Australian Government. Retrieved from https ://www.dss.gov.au/sites/default/files/documents/03_2017/multi cultural_policy_2017.pdf

Australian Human Rights Commission. (2014). Face the facts: Cultural diversity. Retrieved from https://www.humanrights.gov.au/sites/defau It/files/FTFCulturalDiversity.pdf

Bagci, S. C., Stathi, S., \& Piyale, Z. E. (2019). When imagining intergroup contact mobilizes collective action: The perspective of disadvantaged and advantaged groups. International Journal of Intercultural Relations, 69, 32-43. https://doi.org/10.1016/j.ijintrel.2018.12.003

Berry, J. W. (2006). Mutual attitudes among immigrants and ethnocultural groups in Canada. International Journal of Intercultural Relations, 30(6), 719-734. https://doi.org/10.1016/j.jijintrel.2006.06.004

Bourhis, R. V., \& Dayan, J. (2004). Acculturation orientations towards Israeli Arabs and Jewish immigrants in Israel. International Journal of Psychology, 39(2), 118-131. https://doi.org/10.1080/0020759034 4000358 
Branscombe, N. R., Schmitt, M., \& Harvey, R. (1999). Perceiving pervasive discrimination among African Americans: Implications for the group identification and well-being. Journal of Personality and Social Psychology, 77(1), 135-149.

Brylka, A., Mähönen, T. A., Schellhaas, F. M. H., \& Jasinskaja-Lahti, I. (2015). From cultural discordance to support for collective action. Journal of Cross-Cultural Psychology, 46(7), 897-915. https://doi. org $/ 10.1177 / 0022022115589118$

Cantril, H. (1965). The pattern of human concerns. New Brunswick, NJ: Rutgers University Press.

Clarke, J., \& Newman, J. (2017). 'People in this country have had enough of experts': Brexit and the paradoxes of populism. Critical Policy Studies, 11(1), 101-116. https://doi.org/10.1080/19460 171.2017.1282376

Crosby, F. (1976). A model of egoistical relative deprivation. Psychological Review, 83(2), 85-113. https://doi.org/10.1037/0033-295X.83.2.85

Dandy, J., \& Pe-Pua, R. (2010). Attitudes to multiculturalism, immigration and cultural diversity: Comparison of dominant and nondominant groups in three Australian states. International Journal of Intercultural Relations, 34(1), 34-46. https://doi.org/10.1016/j.ijint rel.2009.10.003

Dandy, J., \& Pe-Pua, R. (2013). Beyond mutual acculturation: Intergroup relations among immigrants, Anglo-Australians, and Indigenous Australians/Journal of Psychology. Zeitschrift für Psychologie, 221(4), 232-241. https://doi.org/10.1027/2151-2604/a000153

de la Sablonniere, R., \& Tougas, F. (2008). Relative deprivation and social identity in times of dramatic social change: The case of nurses. Journal of Applied Social Psychology, 38(9), 2293-2314.

de la Sablonniere, R., Tougas, F., \& Lortie-Lussier, M. (2009). Dramatic social change in Russia and Mongolia: Connecting relative deprivation to social identity. Journal of Cross-Cultural Psychology, 40(3), 327-348. https://doi.org/10.1177/0022022108330986

Donnelly, K. (2017, September 29). Multiculturalism and political correctness are killing Australia. Daily Telegraph.

Droogendyk, L., Wright, S. C., Lubensky, M., \& Louis, W. R. (2016). Acting in solidarity: Cross-group contact between disadvantaged group members and advantaged group allies. Journal of Social Issues, 72(2), 315-334. https://doi.org/10.1111/josi.12168

Ellemers, N., \& Bos, A. E. R. (1998). Social identity, relative deprivation, and coping with the threat of position loss: A field study among native shopkeepers in Amsterdam. Journal of Applied Social Psychology, 28(21), 1987-2006. https://doi.org/10.1111/j.1559-1816.1998.tb01357.x

Fozdar, F., Spittles, B., \& Hartley, L. K. (2015). Australia Day, flags on cars and Australian nationalism. Journal of Sociology, 51(2), 317-336. https://doi.org/10.1177/1440783314524846

Hobolt, S. B. (2016). The Brexit vote: A divided nation, a divided continent. Journal of European Public Policy, 23(9), 1259-1277. https://doi. org/10.1080/13501763.2016.1225785

Jack, I. (2016, June 25). In this Brexit vote, the poor turned on an elite who ignored them. The Guardian. Retrieved from https://www.thegu ardian.com/commentisfree/2016/jun/25/brexit-vote-poor-elite

Jetten, J., Mols, F., \& Postmes, T. (2015). Relative deprivation and relative wealth enhances anti-immigrant sentiments: The v-curve re-examined. PLoS ONE, 10(10), e0139156. https://doi.org/10.1371/journ al.pone.0139156

Jupp, J. (2002). From White Australia to Woomera: The story of Australian immigration. Cambridge: Cambridge University Press.

Kessler, T., \& Hollbach, S. (2005). Group-based emotions as determinants of ingroup identification. Journal of Experimental Social Psychology, 41(6), 677-685. https://doi.org/10.1016/j.jesp.2005.01.001

Kobrynowicz, D., \& Branscombe, N. R. (1997). Who considers themselves victims of discrimination?: Individual difference predictors of perceived gender discrimination in women and men. Psychology of Women Quarterly, 21(3), 347-363. https://doi.org/10.1111/j.1471-6402.1997. tb00118.x
Kunovich, R. M. (2009). The sources and consequences of national identification. American Sociological Review, 74, 573-593. https://doi. org/10.1177/000312240907400404

Leach, C. W., lyer, A., \& Pedersen, A. (2007). Angry opposition to government redress: When the structurally advantaged perceive themselves as relatively deprived. British Journal of Social Psychology, 46(Pt 1), 191-204. https://doi.org/10.1348/014466606X99360

LeBlanc, J., Beaton, A. M., \& Walker, I. (2015). The downside of being up: A new look at group relative gratification and traditional prejudice. Social Justice Research, 28(1), 143-167. https://doi.org/10.1007/ s11211-015-0233-y

Louis, W. R., Esses, V. M., \& Lalonde, R. N. (2013). National identification, perceived threat, and dehumanization as antecedents of negative attitudes toward immigrants in Australia and Canada. Journal of Applied Social Psychology, 43, 156-165. https://doi.org/10.1111/jasp.12044

Mackinnon, D. P., Lockwood, C. M., \& Williams, J. (2004). Confidence limits for the indirect effect: Distribution of the product and resampling methods. Multivariate Behavioral Research, 39(1), 99. https://doi. org/10.1207/s15327906mbr3901_4

Major, B., Blodorn, A., \& Major Blascovich, G. (2018). The threat of increasing diversity: Why many White Americans support Trump in the 2016 presidential election. Group Processes \& Intergroup Relations, 21(6), 931-940. https://doi.org/10.1177/1368430216677304

Markus, A. (2017). Mapping social cohesion: The Scanlon Foundation surveys 2017. Melbourne, Australia.: Scanlon Foundation.

McAllister, I. (2018). National identity and attitudes towards immigration in Australia. National Identities, 20(2), 157-173. https://doi. org/10.1080/14608944.2016.1206069

McCauley (Producer). (2016, August 1). Sonia Kruger calls scholarship program 'reverse discrimination'. news.com.au. Retrieved from http:// www.news.com.au/finance/money/costs/sonia-kruger-calls-schol arship-program-reverse-discrimination/news-story/08eac22223 225 ce 80214014712 e3c400

Meuleman, B., Abts, K., Schmidt, P., Pettigrew, T., \& Davidov, E. (2019). Economic conditions, group relative deprivation and ethnic threat perceptions: A cross-national perspective. Journal of Ethnic and Migration Studies, 1-19. https://doi.org/10.1080/13691 83x.2018.1550157

Mols, F., \& Jetten, J. (2016). Explaining the appeal of populist right-wing parties in times of economic prosperity. Political Psychology, 37(2), 275-292. https://doi.org/10.1111/pops.12258

Nagata, D., \& Crosby, F. (1991). Comparisons, justice, and the internment of Japanese-Americans. In J. Suls \& T. A. Wills (Eds.), Social comparison: Contemporary theory and research (pp. 347-368). Hillsdale, NJ: Lawrence Erlbaum Associates Inc.

SBS News. (2016, November 24). Hanson decries reverse racism in Australia. Retrieved from https://www.sbs.com.au/news/hanso n-decries-reverse-racism-in-australia

Noor, M., Shnabel, N., Halabi, S., \& Nadler, A. (2012). When suffering begets suffering: The psychology of competitive victimhood between adversarial groups in violent conflicts. Personality and Social Psychology Review, 16(4), 351-374. https://doi.org/10.1177/10888 68312440048

Norton, M. I., \& Sommers, S. R. (2011). Whites see racism as a zero-sum game that they are now losing. Perspectives on Psychological Science, 6(3), 215-218. https://doi.org/10.1177/1745691611406922

Operario, D., \& Fiske, S. T. (2001). Ethnic identity moderates perceptions of prejudice: Judgments of personal versus group discrimination and subtle versus blatant bias. Personality and Social Psychology Bulletin, 27(5), 550-561. https://doi.org/10.1177/0146167201275004

Pehrson, S., Brown, R., \& Zagefka, H. (2009). When does national identification lead to the rejection of immigrants? Cross-sectional and longitudinal evidence for the role of essentialist in-group definitions. British Journal of Social Psychology, 48(Pt 1), 61-76. https://doi. org/10.1348/014466608X288827 
Petta, G., \& Walker, I. (1992). Relative deprivation and ethnic identity. British Journal of Social Psychology, 31(4), 285-293. https://doi. org/10.1111/j.2044-8309.1992.tb00973.x

Pettigrew, T. F. (2017). Social psychological perspectives on Trump supporters. Journal of Social and Political Psychology, 5(1), 107-116. https://doi.org/10.5964/jspp.v5i1.750

Poore, A. G., Gagne, F., Barlow, K. M., Lydon, J. E., Taylor, D. M., \& Wright, S. C. (2002). Contact and the personal/group discrimination discrepancy in an Inuit community. Journal of Psychology, 136(4), 371-382. https://doi.org/10.1080/00223980209604164

Preacher, K. J., \& Hayes, A. F. (2008). Asymptotic and resampling strategies for assessing and comparing indirect effects in multiple mediator models. Behavior Research Methods, 40(3), 879-891. https://doi. org/10.3758/brm.40.3.879

Reese, G., Proch, J., \& Finn, C. (2015). Identification with all humanity: The role of self-definition and self-investment. European Journal of Social Psychology, 45(4), 426-440. https://doi.org/10.1002/ejsp.2102

Reijerse, A., Van Acker, K., Vanbeselaere, N., Phalet, K., \& Duriez, B. (2013). Beyond the ethnic-civic dichotomy: Cultural citizenship as a new way of excluding immigrants. Political Psychology, 34(4), 611-630. https://doi.org/10.1111/j.1467-9221.2012.00920.x

Riek, B. M., Mania, E. W., \& Gaertner, S. L. (2006). Intergroup threat and outgroup attitudes: A meta-analytic review. Personality and Social Psychology Review, 10(4), 336-353. https://doi.org/10.1207/s1532 7957pspr1004_4

Smith, H. J., \& Ortiz, D. J. (2002). "Is it just me?" The different consequences of personal and group relative deprivation. In I. Walker \& H. J. Smith (Eds.), Relative deprivation: Specification, development, and integration (pp. 91-118). Cambridge: Cambridge University Press.

Smith, H. J., Pettigrew, T. F., Pippin, G. M., \& Bialosiewicz, S. (2012). Relative deprivation: A theoretical and meta-analytic review. Personality and Social Psychology Review, 16(3), 203-232. https://doi. org/10.1177/1088868311430825

Smith, H. J., Ryan, D. A., Jaurique, A., Pettigrew, T. F., Jetten, J., Ariyanto, A., ... Butera, F. (2018). Cultural values moderate the impact of relative deprivation. Journal of Cross-Cultural Psychology, 49(8), 11831218. https://doi.org/10.1177/0022022118784213

Spry, C., \& Hornsey, M. (2007). The influence of blind and constructive patriotism on attitudes toward multiculturalism and immigration. Australian Journal of Psychology, 59(3), 151-158. https://doi. org/10.1080/00049530701449489

Sullivan, D., Landau, M. J., Branscombe, N. R., \& Rothschild, Z. K. (2012). Competitive victimhood as a response to accusations of ingroup harm doing. Journal of Personality and Social Psychology, 102(4), 778795. https://doi.org/10.1037/a0026573

Sumino, T. (2017). National identity and public attitudes toward multiculturalism in Canada: Testing the indirect effect via perceived collective threat. Canadian Journal of Behavioural Science/Revue canadienne des sciences du comportement, 49(3), 183-194. https://doi. org/10.1037/cbs0000076

Tajfel, H. (1978). Differentiation between social groups: Studies in the social psychology of intergroup relations. London, UK: Academic Press.

Taylor, D., Wright, S., Moghaddam, F., \& Lalonde, R. (1990). The personal/group discrimination discrepancy: Perceiving my group, but not myself, to be a target for discrimination. Personality and Social Psychology Bulletin, 16(2), 254-262. https://doi.org/10.1177/01461 67290162006

Tougas, F., \& Beaton, A. (1992). Women's views on affirmative action: A new look at preferential treatmen. Social Justice Research, 5(3), 239-248.
Tougas, F., \& Beaton, A. (2001). Personal and group relative deprivation: Connecting the 'I' to the 'We'. In I. Walker \& H. J. Smith (Eds.), Relative deprivation: Specification, development, and integration (pp. 119-135). New York, NY: Cambridge University Press.

Tougas, F., Beaton, A., \& Veilleux, F. (1991). Why women approve of affirmative action: The study of a predictive model. International Journal of Psychology, 26(6), 761-776. https://doi.org/10.1080/0020759910 8247164

Tropp, L., \& Wright, S. (1999). In-group identification and relative deprivation: An examination across multiple social comparisons. European Journal of Social Psychology, 29(5-6), 707-724. https://doi. org/10.1002/(SICI)1099-0992(199908/09)29:5/6<707:AID-EJSP9 $68>3.0 . C O ; 2-Y$

Turken, R., \& Rudmin, F. W. (2013). On psychological effects of globalization: Development of a scale of global identity. Psychology \& Society, 5(2), 63-89.

van der Bles, A. M., Postmes, T., LeKander-Kanis, B., \& Otjes, S. (2018). The consequences of collective discontent: A new measure of zeitgeist predicts voting for extreme parties. Political Psychology, 39(2), 381-398. https://doi.org/10.1111/pops.12424

van der Bles, A. M., Postmes, T., \& Meijer, R. R. (2015). Understanding collective discontents: A psychological approach to measuring zeitgeist. PLoS ONE, 10(6), e0130100. https://doi.org/10.1371/journ al.pone. 0130100

van Zomeren, M., Postmes, T., \& Spears, R. (2008). Toward an integrative social identity model of collective action: A quantitative research synthesis of three socio-psychological perspectives. Psychological Bulletin, 134(4), 504-535. https://doi.org/10.1037/0033-2909.134.4.504

Vanneman, R. D., \& Pettigrew, T. F. (1972). Race and relative deprivation in the urban United States. Race, 13(4), 461-486. https://doi. org/10.1177/030639687201300404

Verkuyten, M. (2005). Ethnic group identification and group evaluation among minority and majority groups: Ttesting the multiculturalism hypothesis. Journal of Personality and Social Psychology, 88(1), 121138. https://doi.org/10.1037/0022-3514.88.1.121

Verkuyten, M., \& Martinovic, B. (2015). Behind the ethnic-civic distinction: Public attitudes towards immigrants' political rights in the Netherlands. Social Science Research, 53, 34-44. https://doi. org/10.1016/j.ssresearch.2015.05.002

Walker, I. (1999). Effects of personal and group relative deprivation on personal and collective self-esteem. Group Processes \& Intergroup Relations, 2(4), 365-380. https://doi.org/10.1177/1368430299 024004

Walker, I., Leviston, Z., Price, J., \& Devine-Wright, P. (2015). Responses to a worsening environment: Relative deprivation mediates between place attachments and behaviour. European Journal of Social Psychology, 45(7), 833-846. https://doi.org/10.1002/ejsp.2151

\section{SUPPORTING INFORMATION}

Additional supporting information may be found online in the Supporting Information section.

How to cite this article: Leviston Z, Dandy J, Jetten J, Walker I. The role of relative deprivation in majority-culture support for multiculturalism. J Appl Soc Psychol. 2019;00:1-12. https://doi.org/10.1111/jasp.12652 